\title{
Chromatin-regulating genes are associated with postoperative prognosis and isocitrate dehydrogenase mutation in astrocytoma
}

\author{
Kun Zhang ${ }^{1}$, Hongguang Zhao ${ }^{2}$, Kewei Zhang ${ }^{3}$, Cong Hua ${ }^{4}$, Xiaowei Qin ${ }^{4}$, Songbai Xu ${ }^{4}$ \\ ${ }^{1}$ Jilin Provincial Key Laboratory on Molecular and Chemical Genetic, The Second Hospital of Jilin University, Changchun, China; ${ }^{2}$ Department \\ of Nuclear Medicine, The First Hospital of Jilin University, Changchun, China; ${ }^{3}$ Department of Thoracic Surgery, The First Hospital of Jilin \\ University, Changchun, China; ${ }^{4}$ Department of Neurosurgery, The First Hospital of Jilin University, Changchun, China \\ Contributions: (I) Conception and design: S Xu; (II) Administrative support: H Zhao; (III) Provision of study materials or patients: C Hua; (IV) \\ Collection and assembly of data: X Qin, K Zhang; (V) Data analysis and interpretation: K Zhang; (VI) Manuscript writing: All authors; (VII) Final \\ approval of manuscript: All authors. \\ Correspondence to: Songbai Xu. Department of Neurosurgery, The First Hospital of Jilin University, Changchun 130021, China. \\ Email: xusongbai@jlu.edu.cn.
}

Background: Abnormality in chromatin regulation is a major determinant in the progression of multiple neoplasms. Astrocytoma is a malignant histologic morphology of glioma that is commonly accompanied by chromatin dysregulation. However, the systemic interpretation of the expression characteristics of chromatin-regulating genes in astrocytoma is unclear.

Methods: In this study, we investigated the expression profile of chromatin regulation genes in 194 astrocytoma patients sourced from The Cancer Genome Atlas (TCGA) database. The relevance of gene expression and postoperative survival outcomes was assessed.

Results: Based on the expression patterns of chromatin regulation genes, two primary clusters and three subclusters with significantly different survival outcomes were identified. The patients in cluster_1 (or subcluster_1) had a poorer prognosis than the other groups, and this particular cohort were older, with a more advanced grade of tumor and isocitrate dehydrogenase-wildtype distribution. Detection of the differentially expressed genes revealed that the group with poor prognosis was characterized by downregulation of H2AFY2, WAC, HDAC5, ZMYND11, TET1, SATB1, and MYST4, and overexpression of EYA4. Moreover, all eight genes were significantly correlated with overall survival (OS) in astrocytoma. Age-associated genes were investigated and the expression levels of EYA4, TET1, SATB1, WAC, ZMYND11, and $H 2 A F Y 2$ were found to be closely correlated with advanced age. Regression analysis suggested that the expression levels of H2AFY2, HILS1, EYA1, EYA4, and KDMSB were independently associated with IDH mutation status. The differential expressions of 34 common genes were significantly associated with age, grade, and $I D H$ mutant.

Conclusions: The study revealed that the expression pattern of chromatin regulation genes was significantly associated with postoperative prognosis in astrocytoma. Moreover, the differential expression of particular genes was strongly associated with clinical characteristics such as age, grade, and IDH subtype. These results suggest that the genes involved in chromatin regulation play important roles in the biological process of astrocytoma progression, and these molecules could potentially serve as therapeutic targets in astrocytoma.

Keywords: Chromatin regulation; prognosis; IDH mutation; astrocytoma

Submitted Sep 23, 2020. Accepted for publication Nov 13, 2020.

doi: 10.21037/atm-20-7229

View this article at: http://dx.doi.org/10.21037/atm-20-7229 


\section{Introduction}

Diffuse gliomas are characterized by a high incidence rate, poor prognosis, high rates of mortality, and treatment insensitivity (1). Astrocytoma is the main type of low-grade glioma and has relatively high malignancy $(2,3)$. Despite recent advances in multimodality therapy incorporating surgery, chemotherapy, and radiotherapy as the commonly accepted treatments for astrocytoma, little improvement has been seen in patient outcomes $(4,5)$. According to the recent World Health Organization (WHO) classification, grade II-III astrocytomas are divided into isocitrate dehydrogenasewildtype $(I D H$-wt) and $I D H$-mutant $(I D H$-mut) groups, with the former being significantly more aggressive and associated with poorer outcomes (6). Exploration of the molecular characteristics and classification in specific populations is crucial to improving therapy and prognosis for patients with astrocytoma (7). Genetic analyses of glioma tissues have revealed that the development of glioma is closely related to various epigenetic phenomena, including chromatin remodeling $(8,9)$. Due to the reversibility of epigenetic modifications, the various proteins and genes regulating these changes have become potential new targets in the treatment of glioma $(2,10)$.

Chromatin remodeling involves changing the configuration of chromatin structure and is crucial in regulating gene expression, apoptosis, and DNA replication and repair (11). In the process of chromatin remodeling, chromatin regulator proteins act to control alterations in the structure of chromatin. Dysfunctions in chromatin-regulating proteins have been associated with the development and progression of brain tumors $(12,13)$. Multiple studies have shown that specific molecular variations, such as ATRX mutations, have clinical implications for the molecular diagnosis of gliomas and can provide diagnostic and prognostic information (14). However, the expression patterns of genes that regulate chromatin remodeling have not been well studied. To comprehensively understand the biological heterogeneity of astrocytoma, the gene expressions coding chromatinregulating proteins in astrocytoma are in urgent need of systematic study. Given that the deregulation of chromatin structure can be reversed by DNA methylation and histone deacetylation inhibitors, it is possible that identified subgroups with typical gene expression could be treated with targeted therapy to promote the expression of tumor suppressor genes or to suppress the expression of tumor driver genes.
In this study, we focused on the expression distributions of chromatin regulation genes in surgically excised astrocytoma tissue and assessed their relevance to prognosis and clinical outcome. To examine variations associated with clinical features, we identified genes that were differentially expressed or commonly varied. Our findings suggest that chromatin regulation genes have the potential to be promising therapeutic targets. We present the following article in accordance with the REMARK reporting checklist (available at http://dx.doi.org/10.21037/atm-20-7229).

\section{Methods}

\section{Samples and database}

The transcriptome data and corresponding clinical data of low-grade glioma patients were obtained from The Cancer Genome Atlas database (TCGA, cbioportal.org) (15). The data were filtered based on whether the messenger RNA (mRNA) z-score data and clinical features, including overall survival (OS), progression free survival (PFS), disease free survival (DFS), and disease-specific survival (DSS), were complete. Patients who had a postoperative pathological diagnosis and detailed records, including age, sex, grade of tumor, and IDH subtype were enrolled in the current study. All the samples were diagnosed as astrocytoma according to the histological records and RNA sequencing. Finally, 194 astrocytoma samples were enrolled in the study. All procedures performed in this study involving human participants were in accordance with the Declaration of Helsinki (as revised in 2013). All utilized public omics datasets had been generated in previous studies and obtained with prior ethical approval.

\section{Bioinformatics}

Chromatin remodeling genes included in the current analysis were derived from the Uniport-keyword database (KW-0156, uniport.org/keywords) as published (16). A total of 295 genes coding for reviewed proteins associated with chromatin regulation were arrayed, and the expression data (RNA-Seq V2 RSEM) were obtained from the transcriptome of astrocytoma originating from TCGA data. A cluster analysis of the expressions of the 295 genes in the 194 astrocytoma tissues was performed to distinguish samples based on their gene expression profiles. Subjects with similar gene expression patterns were identified from the total sample. The transcription levels were expressed 
as mRNA z-scores and clustered using the hierarchical clustering algorithm using a Stanford program (17). A cluster heat map and pattern were generated with the Java Treeview program according to the tumor stage (18).

\section{Prognostic relevance analyses}

The prognostic role of the chromatin remodeling genes was investigated by comparing the survival outcomes of different groups. Data on overall survival (OS), progressionfree survival (PFS), disease-free survival (DFS), and diseasespecific survival (DSS) were accessed using GraphPad Prism (GraphPad Software, Inc., California, US; Version 8). Comparisons of survival between different clusters were conducted to determine the relevance of gene expression profiles to prognosis. Additionally, an analysis of the difference in OS between cohorts with low and high expression levels of individual genes was conducted using GraphPad Prism 8.

\section{Statistical analysis}

Survival curves of different groups were plotted and compared using the log-rank (Mantel-Cox) test in GraphPad Prism 8 (GraphPad Software, Inc., California, US; Version 8). Differences in clinical characteristics and the variables associated with each cluster were assessed with Fisher's exact test and Spearman's correlation. Differences in the expression levels of genes between clusters were detected with analysis of variance (ANOVA). Regression analyses were performed to determine correlations between variables. All tests were performed with SPSS 24.0 (IBM, Inc., New York, US). A P value $<0.05$ was considered statistically significant.

\section{Results}

The expression profile of chromatin remodeling genes was significantly associated with prognosis

All patient samples were sorted into clusters based on the transcriptional array of chromatin remodeling genes. The mRNA expression levels of 295 protein coding genes involved in controlling the alteration of chromatin structure were assessed (Box S1). A total of 194 patients with complete clinical records were recruited in the cluster analysis. The initial cluster analysis defined 50 patients as primary cluster_1 and 144 patients as primary cluster_2. Cluster_2 was subsequently subdivided into two clusters.
The three clusters are shown in Figure 1A. The difference in prognosis between groups was also assessed. In the dichotomous grouping, cluster_1 showed significantly poorer prognosis than cluster_2, specifically in OS (19.89 vs. 79.99 months, $\mathrm{P}<0.0001)$, DSS (19.89 vs. 93.20 months, $\mathrm{P}<0.0001)$, DFS (23.44 vs. undefined months, $\mathrm{P}=0.0179)$, and PFS (11.51 vs. 43.53 months, $\mathrm{P}<0.0001$ ) (Table 1 and Figure $1 B$ ). In the trichotomous grouping, subcluster_1 showed the worst outcomes in OS $(\mathrm{P}<0.0001)$, DSS $(\mathrm{P}<0.0001)$, and PFS $(\mathrm{P}<0.0001)$. Subcluster_3 showed a significant survival advantage of 145.05 months in both OS and DSS (Table 2). No significant difference was detected in DFS between the subclusters (Table 2 and Figure 1C).

\section{The expression of chromatin remodeling genes differed significantly in different clusters}

To study the gene variations associated with prognosis, the expression levels of chromatin remodeling genes were statistically analyzed between each cluster. A comparison of gene expressions between the two primary clusters revealed that the expression of 193 genes varied significantly $(\mathrm{P}<0.05$, Figure $2 A)$. Additional analysis of the differences in gene expression between the three subclusters showed 270 discrepant genes $(\mathrm{P}<0.05$, Figure $2 B)$. Among these, 192 genes were verified as overlaps in the two different gene sets (Figure 2C). Compared to the other clusters, the cohort with a poor prognosis (cluster_1 or subcluster_1) was significantly characterized by low expression levels of H2AFY2, WAC, HDAC5, ZMYND11, TET1, SATB1, and MYST4, and high expression levels of EYA4 (Figure 2A,B).

In the comparison of survival across individual subclusters, both OS and DSS extended gradually from subcluster_1 to subcluster_3. To uncover the genes correlated with prognosis in astrocytoma, changes in the expression of chromatin regulation genes across the three subclusters were assessed. The expressions of 24 genes, represented by $H D A C 5$, were found to be positively correlated with subcluster in order of improved prognosis $(\mathrm{r}>0.4, \mathrm{P}<0.001)$. Conversely, the expressions of 26 genes, represented by $P R K A A 1$ and $R B L 1$, were negatively correlated with subcluster order, from the worst to the best prognosis $(\mathrm{r}<-0.4, \mathrm{P}<0.001)$ (Figure $2 D$ and Table 3).

\section{The prognostic role of individual chromatin-regulating genes in astrocytoma}

Comparison between the different clusters and subclusters 
A

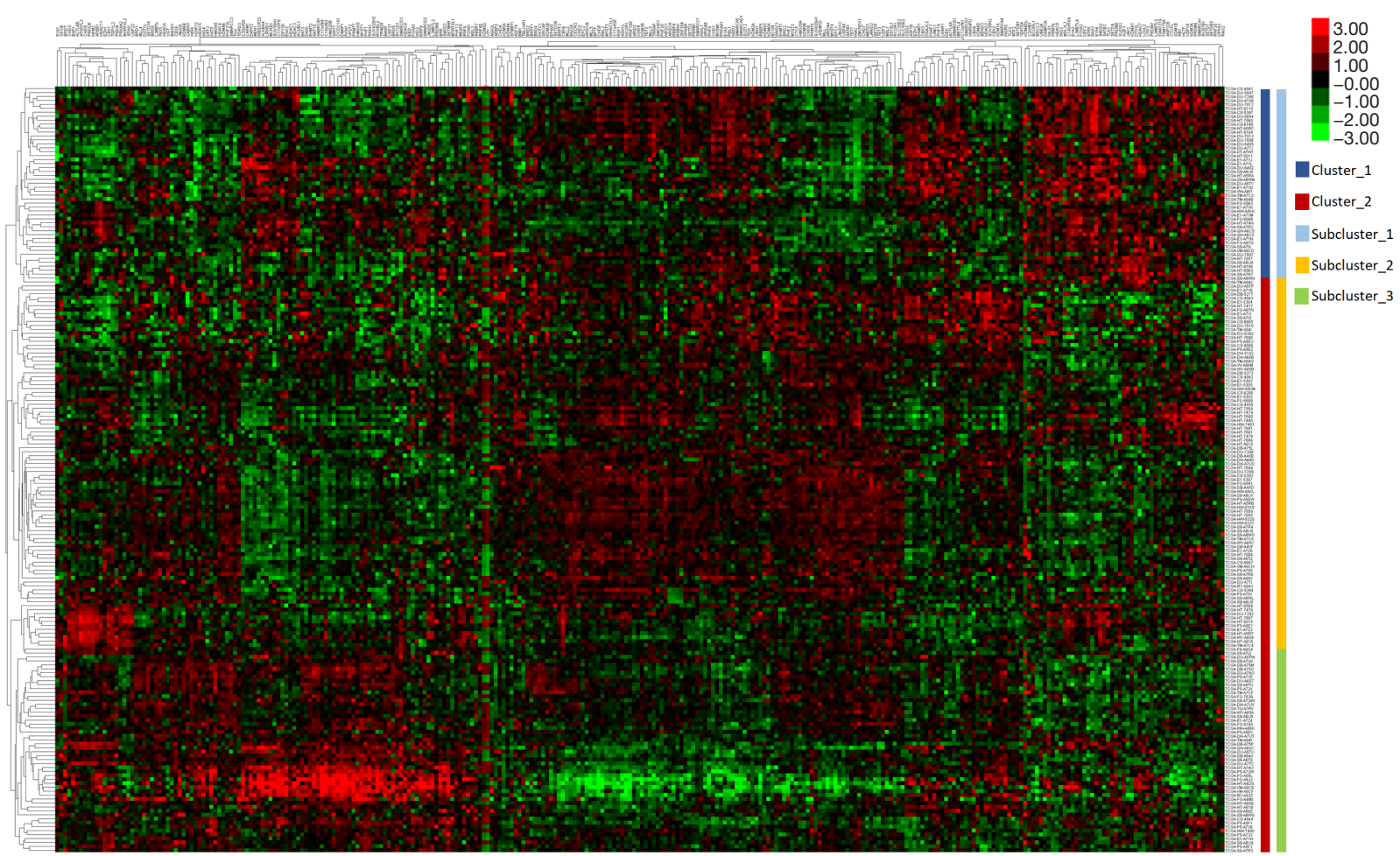

B

OS vs. C1C2

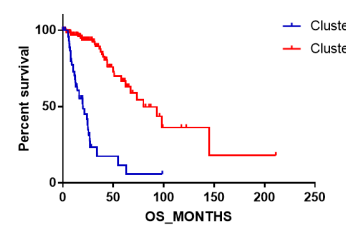

DFS vs. C1C2

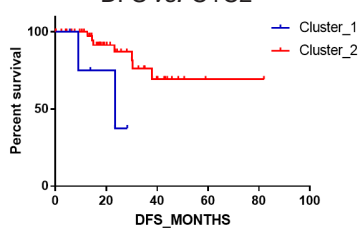

DSS vs. C1C2

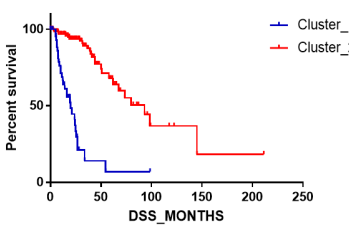

PFS vs. C1C2

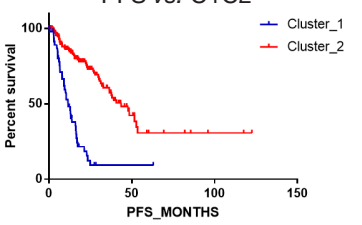

C

OS vs. $\mathrm{C} 1 \mathrm{C} 2 \mathrm{C} 3$

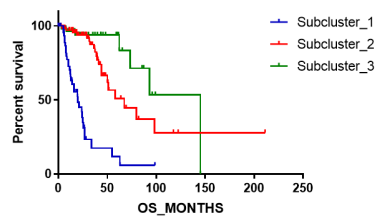

DFS vs. C1C2C3

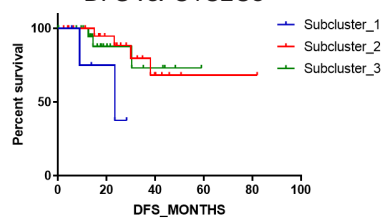

DSS vs. $\mathrm{C} 1 \mathrm{C} 2 \mathrm{C} 3$

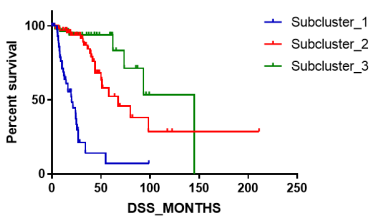

PFS vs. $\mathrm{C} 1 \mathrm{C} 2 \mathrm{C} 3$

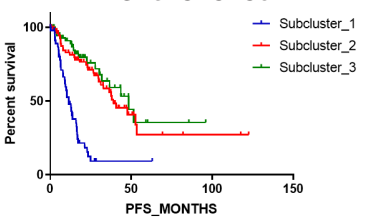

Figure 1 The identified subgroups in relation to the different distributions of chromatin regulation genes in astrocytoma. (A) The different distributions of genes in the dichotomous and trichotomous groups; (B) the overall survival (OS), progression free survival (PFS), disease free survival (DFS) and disease-specific survival (DSS) of cluster 1 and cluster 2 in the dichotomous groups; (C) the OS, DSS, DFS, and PFS of each subcluster in the trichotomous group.

revealed that the expression profile of chromatin regulated genes was closely related to prognosis. Additionally, analysis of the differentially expressed genes showed that eight genes were significantly and commonly changed in both the dichotomous and trichotomous groups. To investigate the effect of individual genes on the prognosis of astrocytoma, the patients were divided into two groups, the high- and low-expression groups, according to the expression levels of these eight genes. Comparisons of OS between the paired groups revealed that low expression levels of $H 2 A F Y 2, W A C$, HDAC5, ZMYND11, TET1, SATB1, and MYST4 were significantly associated with shorter $\mathrm{OS}(\mathrm{P}<0.05$, Figure 3$)$. 
Table 1 Comparison of survival in the dichotomous grouping

\begin{tabular}{|c|c|c|c|c|c|}
\hline & $\begin{array}{l}\text { Median survival of } \\
\text { cluster_1 }\end{array}$ & $\begin{array}{l}\text { Median survival of } \\
\text { cluster_2 }\end{array}$ & Hazard ratio & $95 \% \mathrm{Cl}$ of ratio & $P$ value \\
\hline os & 19.89 & 79.99 & 6.405 & 3.128 to 13.12 & $<0.0001^{\star * *}$ \\
\hline DSS & 19.89 & 93.20 & 6.731 & 3.158 to 14.35 & $<0.0001^{\star \star \star}$ \\
\hline DFS & 23.44 & Undefined & 5.307 & 0.273 to 103.2 & $0.0179^{\star}$ \\
\hline
\end{tabular}

${ }^{*}, \mathrm{P}<0.05 ;{ }^{* \star *}, \mathrm{P}<0.001$.

Table 2 Comparison of survival in the trichotomous grouping.

\begin{tabular}{lcccc}
\hline & Median survival of cluster_1 & Median survival of cluster_2 & Median survival of cluster_3 & P value \\
\hline OS & 19.89 & 67.46 & 145.05 & $<0.0001^{\star \star \star}$ \\
DSS & 19.89 & 67.46 & 145.05 & $<0.0001^{\star \star *}$ \\
DFS & 23.44 & Undefined & Undefined & 0.0597 \\
PFS & 11.51 & 38.93 & 48.49 & $<0.0001^{\star \star *}$ \\
\hline
\end{tabular}

***, $\mathrm{P}<0.001$.

Among these genes, the high expression of $H 2 A F Y 2$ was positively correlated with OS (24.39 vs. 79.99 months, $\mathrm{P}<0.0001 ; \mathrm{HR}=4.16,95 \%$ CI: 2.198-7.871) (Table 3). In contrast, high expression of EYA4 was significantly correlated with poorer prognosis $(\mathrm{P}<0.0001$, Figure 4$)$. Patients with low expression of EYA4 had a median OS of 93.20 months, compared to 24.39 months for those with high expression (HR $=0.21,95 \%$ CI: 0.112-0.383, Table 3).

\section{The chromatin regulation gene variations associated with clinical characteristics in astrocytoma}

To assess the correlation between chromatin remodeling genes and the clinical characteristics of astrocytoma, comparisons of age, sex, grade, and $I D H$-mut status were performed between each cluster and subcluster. In the dichotomous group, there were no differences in sex $(\mathrm{P}>0.05)$; however, significant differences were found in age, grade, and $I D H$ subtype $(\mathrm{P}<0.001)$. Cluster_1 was significantly older $(52.3 \pm 12.53$ vs. $38.17 \pm 10.49$ years, $\mathrm{P}<0.001)$, with more advanced-grade tumors $(92.0 \%$ vs. $59.0 \%$ of $\mathrm{G} 3, \mathrm{P}<0.001)$ and more $I D H$-wt subtype distribution $(88.0 \%$ vs. $9.0 \%, \mathrm{P}<0.001)$ than cluster_2 (Table 4). Similarly, subcluster_1 was significantly older $(52.3 \pm 12.53$ vs. $37.21 \pm 9.61$ and $39.40 \pm 11.49$ years, $\mathrm{P}<0.001)$, with more advanced-grade tumors $(92.0 \%$ vs. $65.4 \%$ and
$50.8 \%$ of $\mathrm{G} 3, \mathrm{P}<0.001$ ) and higher levels of the $I D H$-wt genotype $(88.0 \%$ vs. $6.2 \%$ and $12.7 \%$ of $\mathrm{WT}, \mathrm{P}<0.001)$ than subcluster_2 and subcluster_3. No difference in sex distribution was detected in the trichotomous group $(\mathrm{P}>0.05)$ (Table 5).

The differences in chromatin regulation gene expression $\geq$ are associated with age, grade, and IDH subtype $\leq$ distribution in astrocytoma

The differences in gene expression were assessed in order to detect which genes contributed to the differences in clinical characteristics. OS was compared between patients of different ages, and younger patients (aged $<48$ years) were found to have significantly prolonged OS compared to older patients (aged $\geq 48$ years) (99.06 vs. 54.77 months, $\mathrm{P}=0.035$, Figure $3 A$ ). Correlation analysis revealed that the variations of 79 molecules were significantly correlated with age difference in astrocytoma $(r>0.2$ or $<-0.2, \mathrm{P}<0.05)$ (Figure 3B). Among them, the expressions of 24 genes were positively correlated with increased age, and 57 gene expressions were negatively correlated with increased age (Figure 3C). A strong positive correlation was found between EYA4 and age, while TET1, SATB1, WAC, ZMYND11, and H2AFY 2 showed a strong negative correlation ( $r>0.4$ or $<-0.4, \mathrm{P}<0.0001)$. 
A
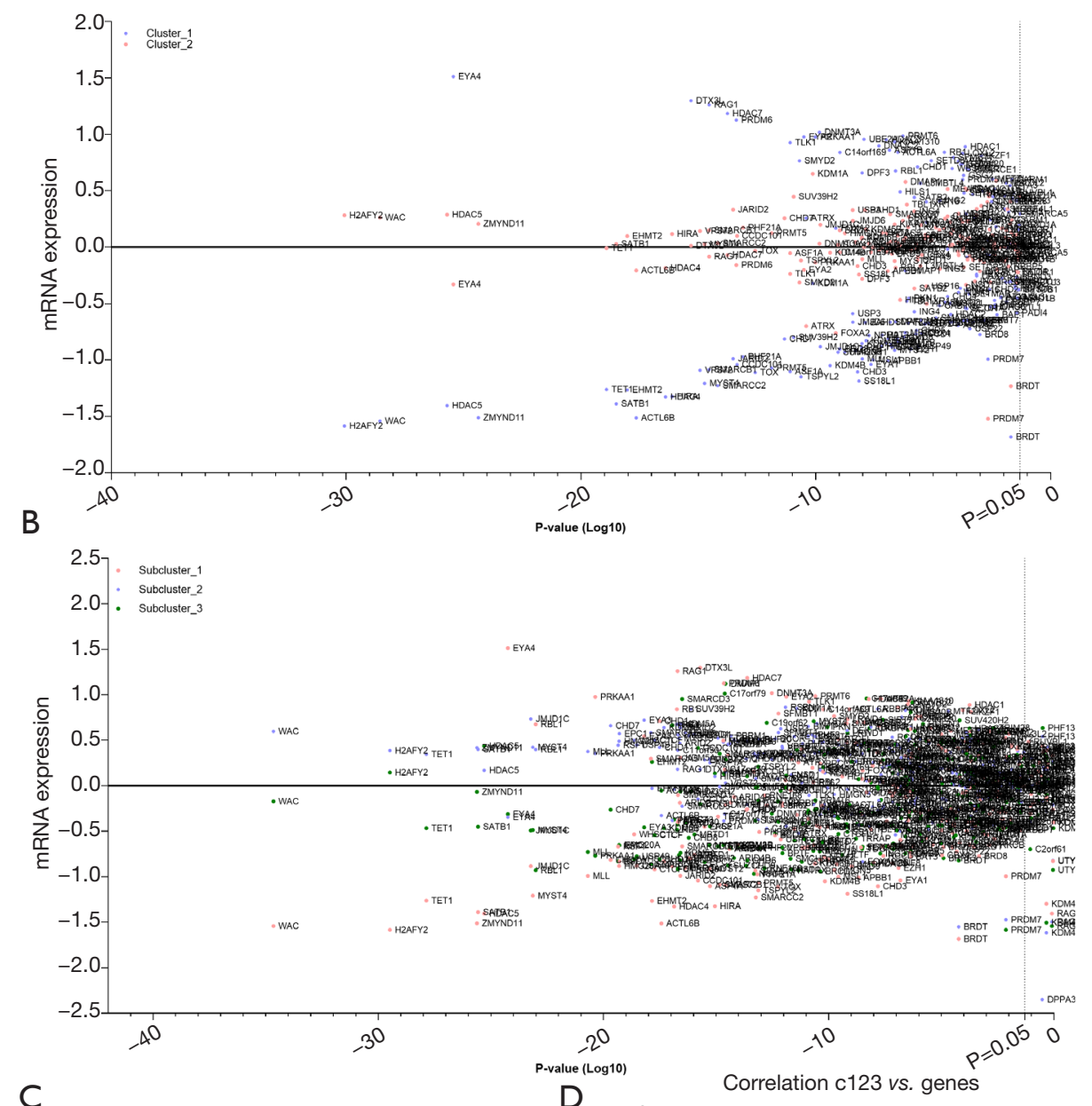

C

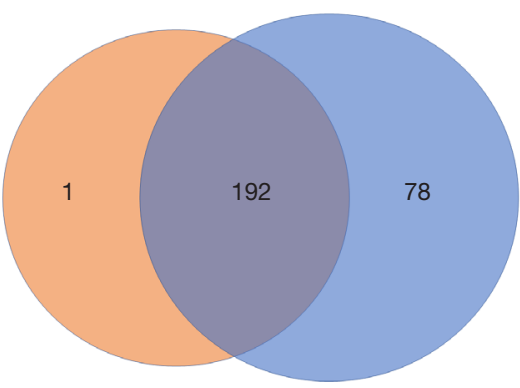

D

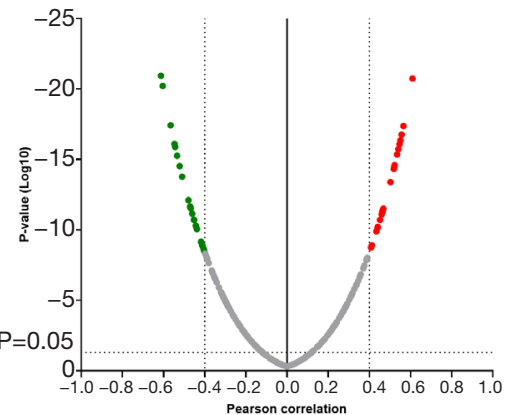

Figure 2 Differentially expressed chromatin regulation genes in astrocytoma. (A) Differentially expressed genes between the dichotomous groups; (B) differentially expressed genes between the trichotomous groups; (C) the overlap of the dichotomous and trichotomous groups; (D) the gene expressions correlated with subcluster changes.

Additionally, prognostic comparisons of different grades of tumor revealed that patients with G2 grade disease showed significantly favorable OS compared to G3 patients (145.10 vs. 43.89 months, $\mathrm{P}<0.0001)$ (Figure 5A). An assessment of grade-correlated genes showed that 110 genes involved in chromatin change varied significantly between G2 and G3 grades (Figure 5B). The prognostic differences between the $I D H$ subtypes (WT and mutant) were 
Table 3 The survival correlation of individual chromatin-regulating genes

\begin{tabular}{|c|c|c|c|c|c|}
\hline & Low expression & High expression & $P$ value & Hazard ratio & $95 \% \mathrm{Cl}$ of ratio \\
\hline WAC & 26.93 & 79.99 & $<0.0001^{\star \star \star \star}$ & 3.21 & 1.837 to 5.611 \\
\hline HDAC5 & 29.13 & 73.48 & $<0.0001^{* * * *}$ & 3.06 & 1.746 to 5.361 \\
\hline ZMYND11 & 31.59 & 93.2 & $<0.0001^{\star \star \star \star}$ & 2.86 & 1.653 to 4.933 \\
\hline TE1 & 37.38 & 67.46 & $0.0024^{\star *}$ & 2.20 & 1.312 to 3.696 \\
\hline SATB1 & 33.96 & 67.46 & $0.0106^{*}$ & 1.92 & 1.123 to 3.285 \\
\hline EYA4 & 93.20 & 24.39 & $<0.0001^{\star \star \star \star *}$ & 0.21 & 0.112 to 0.383 \\
\hline
\end{tabular}

${ }^{\star \star \star *}, \mathrm{P}<0.0001 ;{ }^{* *}, \mathrm{P}<0.01 ;{ }^{*}, \mathrm{P}<0.05$.

investigated; patients with $I D H$-mut type showed significantly prolonged OS (79.99 months), while those with $I D H$-wt type showed much worse OS $(21.30$ months, $\mathrm{P}<0.0001)$ (Figure 5C). A comparison of gene expressions between the two types indicated that 203 genes were significantly associated with $I D H$-mut (Figure $5 D$ ). To detect the overlap of gene sets with regard to age, grade, and $I D H$ subtype, 34 common elements associated with differences in clinical characteristics were identified in astrocytoma (Figure 5E) and these genes are listed in Table 6. A regression analysis was conducted to verify the relevance of chromatin regulation genes and $I D H$-mut, with the results indicating that 5 genes (H2AFY2, HILS1, EYA1, EYA4, and KDMSB) were independently related to IDH-mut status. Moreover, the attribution of $I D H$ subtypes was assessed, and a 5-gene model was found to be capable of distinguishing between the $I D H$-wt and $I D H$-mut subtypes (Figure 6A). Among these genes, the expression levels of $H 2 A F Y 2, E Y A 1$, and $K D M 5 B$ were significantly higher in the $I D H$-mut type, whereas, the expression levels of HILS1 and EYA4 were significantly higher in the $I D H$-wt type (Figure $6 B, C, D, E, F$ ).

\section{Discussion}

Glioma is one of the most common primary brain malignancies and has a high mortality rate (19). Current treatment involves surgical resection followed by chemotherapy and radiotherapy. However, patient outcomes remain disappointing (20). Low-grade astrocytoma is a relatively slow-growing histological type of glioma but has an extremely heterogeneous clinical manifestation (21). Many studies have been conducted on specific populations; however, the identification of specific subgroups and the targeted management of astrocytoma remain inadequate. Classifying patients with astrocytoma on the basis of their genetic features is important for predicting their prognoses after surgery and improving treatment strategies. Chromatin remodeling, the changing configuration of chromatin structure, is crucial in the regulation of gene expression, apoptosis, and DNA replication and repair. Dysfunctions in chromatin-remodeling mechanisms have been associated with disease development and, in particular, alterations in chromatin structure can lead to the deregulated expression of tumor suppressor genes or oncogenes, and cancer initiation (22). The present study was conducted to investigate the expression patterns of chromatin regulation genes in samples from different populations, in an effort to distinguish specific gene expression profiles.

Two primary clusters and three subclusters of astrocytoma patients were identified. Significant differences in prognosis between each group were revealed by comparisons of OS, DSS, DFS, and PFS. Cluster_1 (or subcluster_1) had the worst survival (19.89 months of OS) of any cluster or subcluster. Further analysis of the different gene expressions between the clusters and subclusters revealed that 191 overlapped genes were significantly varied in astrocytoma (Figure 2C). Moreover, the cohort with poor prognosis demonstrated low expression levels of $H 2 A F Y 2$, WAC, HDAC5, ZMYND11, TET1, SATB1, and MYST4, and high expression levels of EYA4. These results suggest that changes in genes involved in chromatin regulation are potentially relevant to the clinical manifestation and outcomes of astrocytoma. The prognostic roles of eight differentially expressed genes were also investigated. High expression levels of H2AFY2, WAC, HDAC5, ZMYND11, TET1, SATB1, and MYST4 were significantly related to 
A

H2AFY2 OS

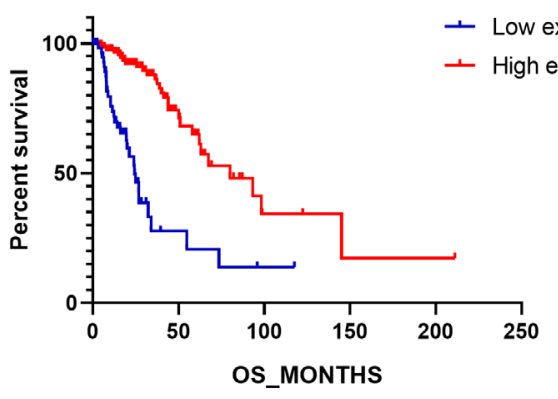

C

HDAC5 OS

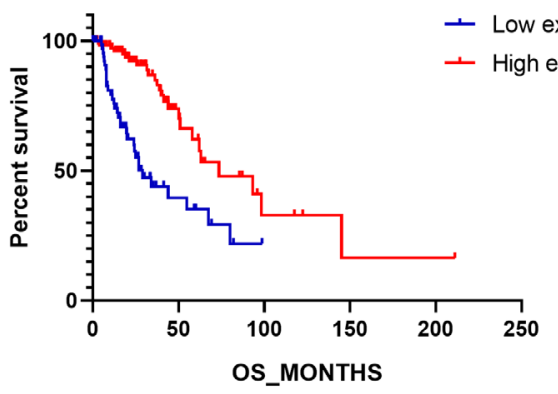

E

TET1 OS

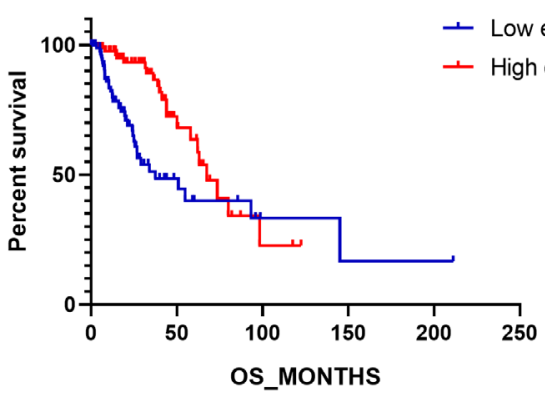

G

MYST4 OS

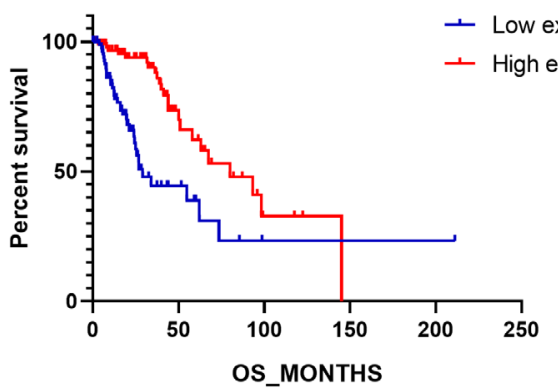

B

WAC OS

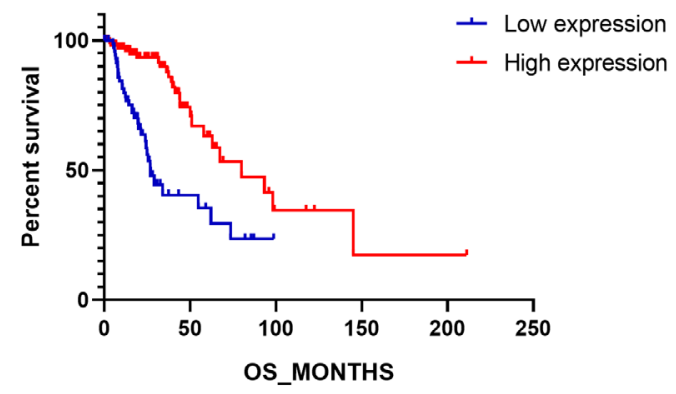

D ZMYND11 OS

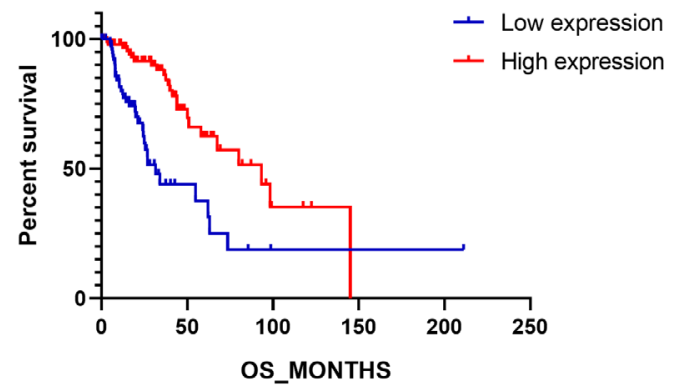

F

SATB1 OS

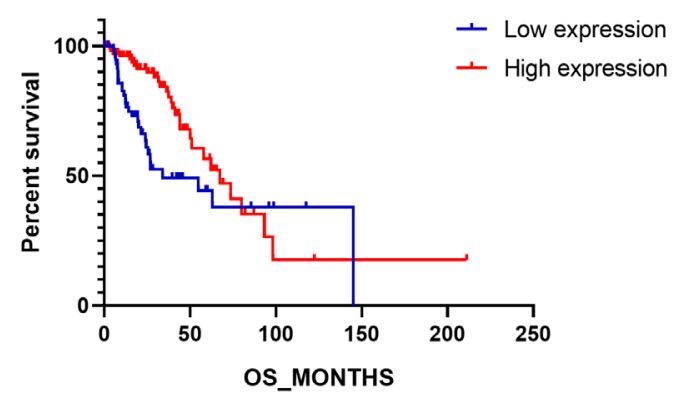

$\mathrm{H}$

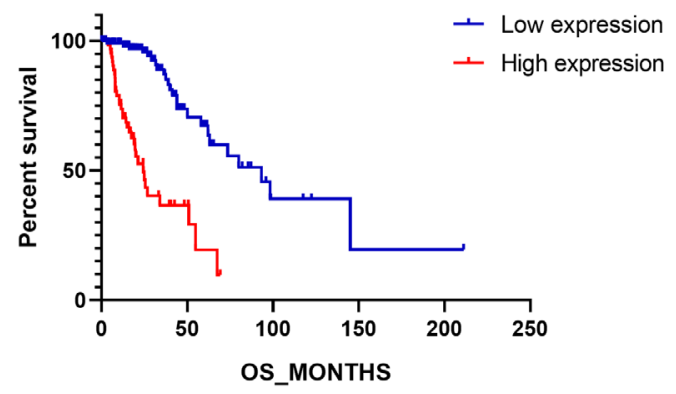

Figure 3 Comparison of overall survival (OS) in patients with different gene expression. (A,B,C,D,E,F,G,H) The OS of patients with high gene expression levels versus those with low gene expression levels. 
A

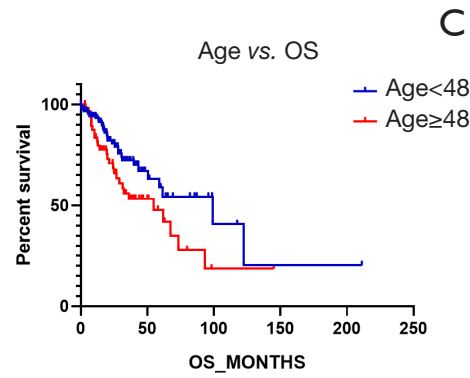

B

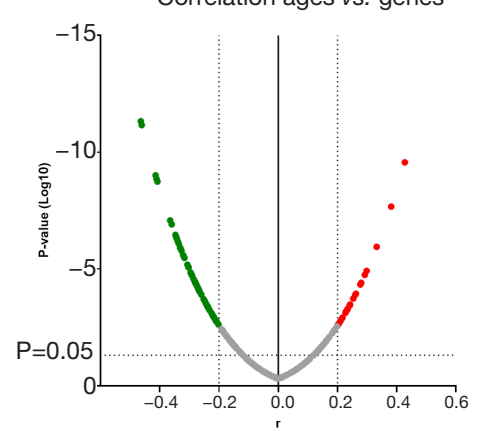

C

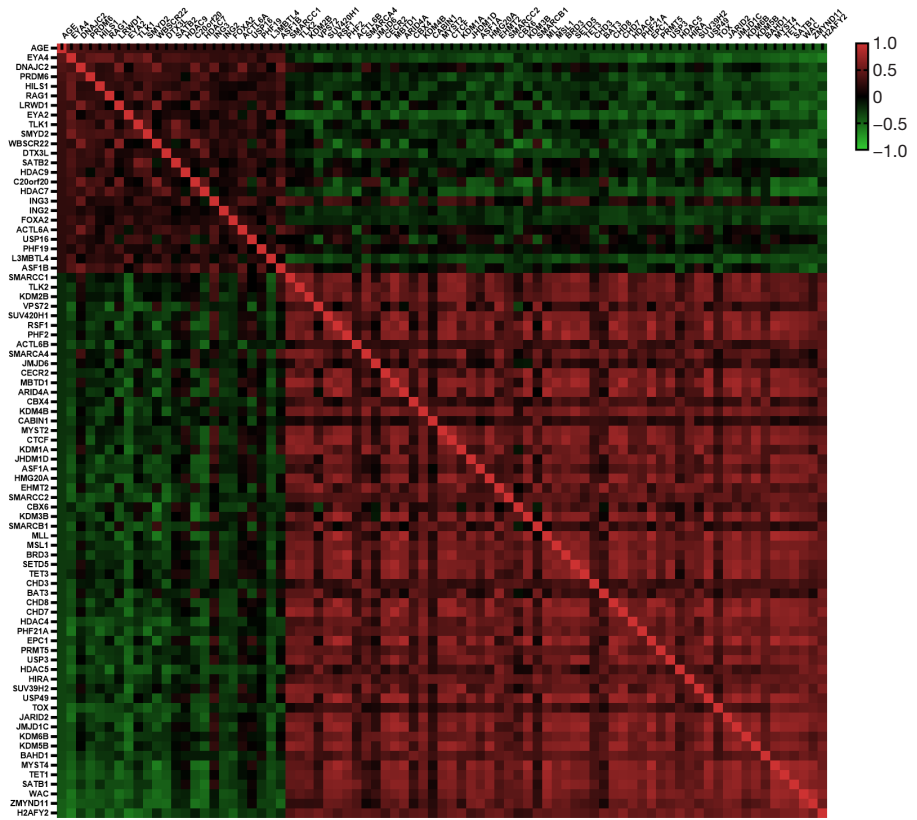

Figure 4 Differential expressions of chromatin regulation genes correlated with increasing age in astrocytoma. (A) Discrepancies in overall survival (OS) between different ages; (B) the gene expressions correlated with age change; (C) the heat map of Pearson's correlation analysis between age change and gene expression.

Table 4 Comparison of clinical characteristics in the dichotomous grouping

\begin{tabular}{lccc}
\hline & Cluster_1 $(n=50)$ & Cluster_2 $(n=144)$ & P value \\
\hline Age (years) & $52.3 \pm 12.53$ & $38.17 \pm 10.49$ & $4.02 \mathrm{E}-13^{* \star \star \star}$ \\
Sex & & & 0.96 \\
Female & $22(44.0 \%)$ & $64(44.4 \%)$ & \\
Male & $28(56.0 \%)$ & $80(55.6 \%)$ & $1.79 \mathrm{E}-05^{\star \star \star \star}$ \\
Grade & & & \\
G2 & $4(8.0 \%)$ & $59(41.0 \%)$ & $3.63 \mathrm{E}-24^{* \star \star \star}$ \\
G3 & $46(92.0 \%)$ & $85(59.0 \%)$ & \\
IDH subtype & $6(12 \%)$ & $129(89.6 \%)$ & \\
Mutant & $44(88.0 \%)$ & $13(9.0 \%)$ & \\
WT & $0(0)$ & $2(1.4 \%)$ & \\
NA & &
\end{tabular}

****, $\mathrm{P}<0.0001 . \mathrm{IDH}$, isocitrate dehydrogenase.

favorable OS in astrocytoma. Strikingly, the hazard ratio of $H 2 A F Y 2$ expression was as high as 4.16. In contrast to other genes, the high expression of EYA4 was significantly correlated with short-term survival, and the hazard ratio was as low as 0.21 . These results reveal the significant potential prognostic role that genes involved in chromatin regulation may play in astrocytoma.

There was a gradual improvement in survival from subcluster_1 to subcluster_3. Therefore, we examined the differences in gene expression correlated with these subcluster 
Table 5 Comparison of clinical characteristics in the trichotomous grouping.

\begin{tabular}{|c|c|c|c|c|}
\hline & Cluster $1(n=50)$ & Cluster $2(\mathrm{n}=81)$ & Cluster $3(n=63)$ & $P$ value \\
\hline Sex & & & & 0.94 \\
\hline Female & $22(44.0 \%)$ & $35(43.2 \%)$ & $29(46.0 \%)$ & \\
\hline Male & $28(56.0 \%)$ & $46(56.8 \%)$ & $34(54.0 \%)$ & \\
\hline G2 & $4(8.0 \%)$ & $28(34.6 \%)$ & $31(49.2 \%)$ & \\
\hline G3 & $46(92.0 \%)$ & $53(65.4 \%)$ & $32(50.8 \%)$ & \\
\hline IDH subtype & & & & $1.45 \mathrm{E}-22^{* \star \star *}$ \\
\hline Mutant & $5(12 \%)$ & 71 (91.4\%) & $55(87.3 \%)$ & \\
\hline
\end{tabular}

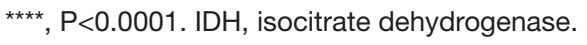

changes. Importantly, 24 genes were found to be positively correlated with the subcluster order and 26 genes were negatively correlated with the subcluster order (Table S1). The genes associated with these subcluster orders included the eight differently expressed genes mentioned previously, which confirms the potential prognostic roles of these genes in astrocytoma.

When comparing clinical characteristics between the defined clusters in astrocytoma, we discovered differing distributions in age, grade and $I D H$ genotype according to cluster. Compared to patients with a favorable prognosis, the poor prognostic cohort (Cluster_1 or Subcluster_1) was significantly older (mean $=52.3$ years), had more advancedgrade tumors (92\% G3), and exhibited widely distributed non-mutant $I D H$ genotype ( $88 \% I D H$-wt). Identification of the genes associated with age revealed that EYA4 was strongly and positively correlated with older age, while TET1, SATB1, WAC, ZMYND11, and H2AFY2 showed a strong negative correlation with older age. All of these genes that were correlated with age were also found in the differentially expressed gene inter-cluster noted above. It is common knowledge that advanced tumor grades are associated with worse prognosis in multiple carcinomas. In the current study, we confirmed that G2 astrocytoma shows a considerably favorable prognosis compared to G3 (145.10 vs. 43.89 months). Moreover, the assessment of differentially expressed genes between patients with different tumor grades revealed that 110 genes involved in chromatin changes were significantly associated with grade progression.

$I D H$ mutations are initiating events that define major clinical and prognostic classes of gliomas (23). Previous studies have identified an IDH mutant-enriched subtype of cholangiocarcinoma with low expression levels of chromatin remodeling genes (24). However, the molecular features of the $I D H$-mut population in astrocytoma are largely unknown. In this study we identified that the poor-survival cohort was significantly associated with $I D H$ subtype. Patients with the $I D H$-mut subtype were also discovered to exhibit high expression levels of $H 2 A F Y 2, E Y A 1$, and $K D M 5 B$, and low expression levels of HILS1 and EYA4, compared to those with $I D H$-wt. These results suggest that chromatin modification is linked to basic biological events that are also regulated by $I D H$ mutations in astrocytoma.

In this study, we found that $H 2 A F Y 2$ (core histone macro-H2A.2 coding gene) and EYA4 (Eyes Absent Homologue 4 coding gene) play a significant role in astrocytoma. $H 2 A F Y 2$, which is involved in transcriptional repression, was found to be associated with prognosis and is significantly correlated with increased age and $I D H$ mut status. However, this gene has not been studied in glioma before, so there is no prior evidence to support the interactions of $H 2 A F Y 2$ and $I D H$ mutation. In previous research, $H 2 A F Y 2$ has been reported to be differentially expressed and co-expressed with noncoding RNAs LOC286002 in breast cancer (25). In another study on nervous system disease, $H 2 A F Y 2$ was specifically downregulated by the $H D A C$ inhibitors (26). The 
A

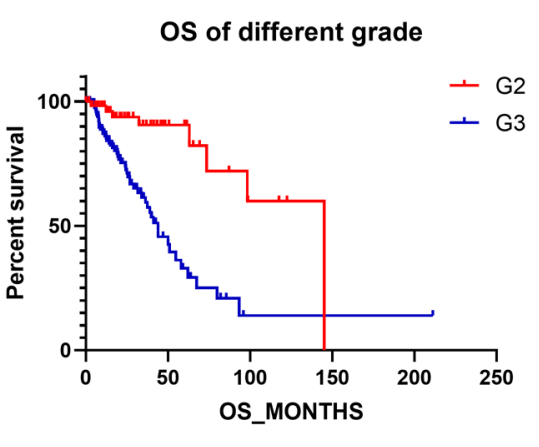

C

OS of different IDH subtype

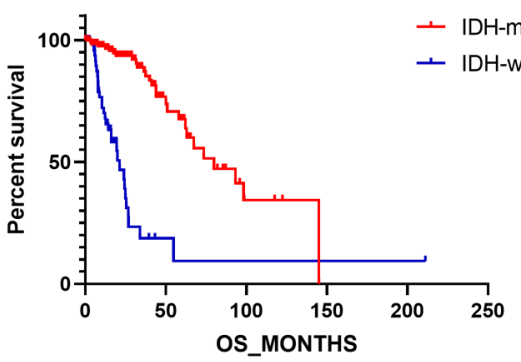

$E$

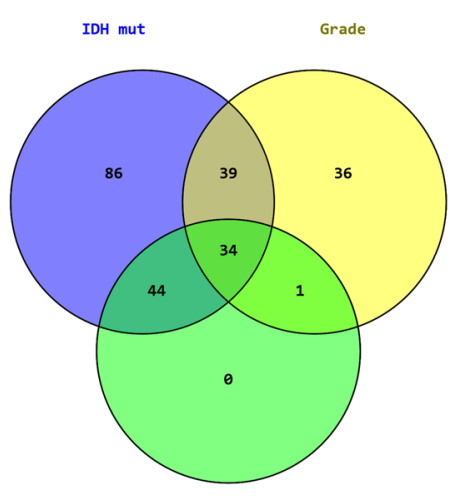

Age
B
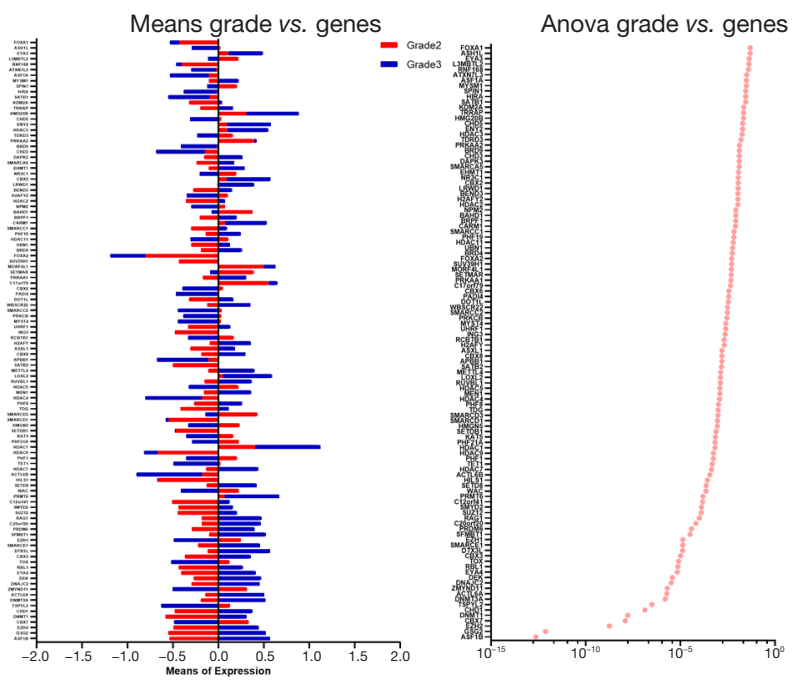

Means IDH vs. genes
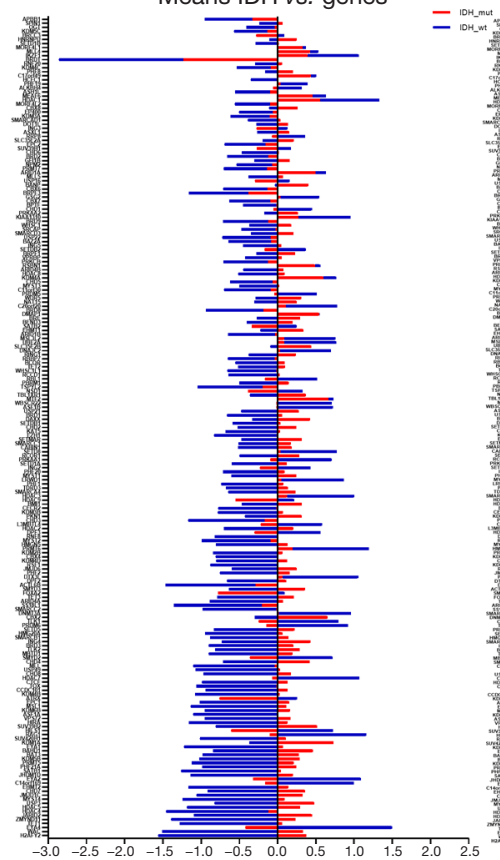

Anova grade vs. genes

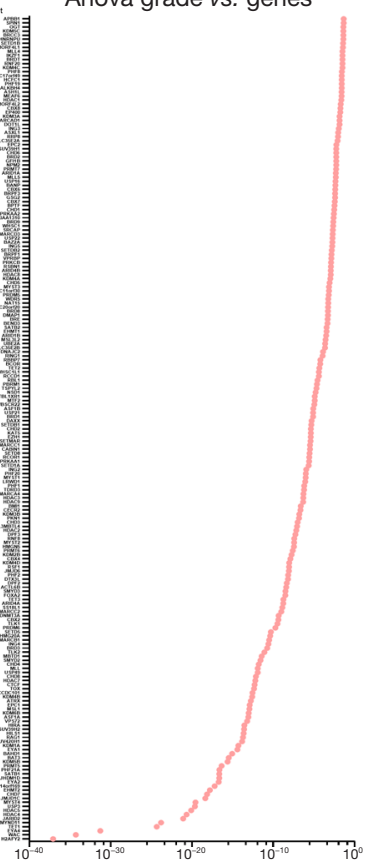

Figure 5 Differences in the expression levels of genes correlated with grade and IDH mutation in astrocytoma. (A) The survival differences between G2 and G3 grades; (B) the differentially expressed genes relevant to differences in grade (C) the survival differences between the $I D H$-mut and $I D H$-wt subtypes; (D) the differentially expressed genes relevant to $I D H$-mut status; (E) the overlap of differentially expressed genes associated with age, tumor grade, and IDH-mut. IDH, isocitrate dehydrogenase.

expression changes indicate the relevance of $H 2 A F Y 2$ and $H D A C s$. Our results showed that, in astrocytoma, the expression levels of $H 2 A F Y 2$ were positively correlated with HDAC5 $(\mathrm{r}=0.629, \mathrm{P}<0.0001)$. Our data also revealed that the expression of $H D A C 5$ was positively implicated with OS in astrocytoma (29.13 vs. 73.48 months, $\mathrm{P}<0.0001$, HR
$=3.06$, 95\% CI: $1.746-5.361$ ), and this result is consistent with the findings of previous research (27). In contrast, a previous study reported that $H D A C 5$ expression was significantly upregulated in high-risk medulloblastoma in comparison with low-risk medulloblastoma and is associated with poor survival (28). We attribute this discrepancy to 
Table 6 Genes involved in chromatin regulation which are significantly associated with clinical features in astrocytoma

\begin{tabular}{|c|c|c|}
\hline Entry name & Protein names & Gene names \\
\hline PRDM6 & $\begin{array}{l}\text { Putative histone-lysine N-methyltransferase PRDM6 (EC 2.1.1.361) (PR } \\
\text { domain zinc finger protein 6) (PR domain-containing protein 6) }\end{array}$ & PRDM6, PFM3 \\
\hline PF21A & PHD finger protein 21A (BHC80a) (BRAF35-HDAC complex protein BHC80) & PHF21A, BHC80, KIAA1696, BM-006 \\
\hline WAC & WW domain-containing adapter protein with coiled-coil & WAC, KIAA1844 \\
\hline PHF19 & PHD finger protein 19 (Polycomb-like protein 3) (hPCL3) & PHF19, PCL3 \\
\hline HDAC7 & Histone deacetylase 7 (HD7) (EC 3.5.1.98) (Histone deacetylase 7A) (HD7a) & $H D A C 7, H D A C 7 A$ \\
\hline ACL6B & $\begin{array}{l}\text { Actin-like protein 6B (53 kDa BRG1-associated factor B) (Actin-related } \\
\text { protein Baf53b) (ArpNalpha) (BRG1-associated factor 53B) (BAF53B) }\end{array}$ & ACTL6B, ACTL6, BAF53B \\
\hline ASF1A & $\begin{array}{l}\text { Histone chaperone ASF1A (Anti-silencing function protein } 1 \text { homolog A) } \\
\text { (hAsf1) (hAsf1a) (CCG1-interacting factor A) (CIA) (hCIA) }\end{array}$ & ASF1A, CGI-98, HSPC146 \\
\hline HIRA & Protein HIRA (TUP1-like enhancer of split protein 1) & HIRA, DGCR1, HIR, TUPLE1 \\
\hline FOXA2 & $\begin{array}{l}\text { Hepatocyte nuclear factor 3-beta (HNF-3-beta) (HNF-3B) (Forkhead box } \\
\text { protein A2) (Transcription factor 3B) (TCF-3B) }\end{array}$ & FOXA2, HNF3B, TCF3B \\
\hline ING3 & Inhibitor of growth protein 3 (p47ING3) & ING3, HSPC301 \\
\hline HDAC4 & Histone deacetylase 4 (HD4) (EC 3.5.1.98) & HDAC4, KIAA0288 \\
\hline HDAC5 & Histone deacetylase 5 (HD5) (EC 3.5.1.98) (Antigen NY-CO-9) & HDAC5, KIAA0600 \\
\hline ZMY11 & $\begin{array}{l}\text { Zinc finger MYND domain-containing protein } 11 \text { (Adenovirus } 5 \text { E1A-binding } \\
\text { protein) (Bone morphogenetic protein receptor-associated molecule 1) } \\
\text { (Protein BS69) }\end{array}$ & ZMYND11, BRAM1, BS69 \\
\hline EYA4 & Eyes absent homolog 4 (EC 3.1.3.48) & EYA4 \\
\hline
\end{tabular}

Table 6 (continued) 
Table 6 (continued)

\begin{tabular}{|c|c|c|}
\hline Entry name & Protein names & Gene names \\
\hline CHD3 & $\begin{array}{l}\text { Chromodomain-helicase-DNA-binding protein } 3 \text { (CHD-3) (EC 3.6.4.12) (ATP- } \\
\text { dependent helicase CHD3) (Mi-2 autoantigen } 240 \text { kDa protein) (Mi2-alpha) } \\
\text { (Zinc finger helicase) (hZFH) }\end{array}$ & CHD3 \\
\hline CBX6 & Chromobox protein homolog 6 & CBX6 \\
\hline SMRC2 & $\begin{array}{l}\text { SWI/SNF complex subunit SMARCC2 (BRG1-associated factor 170) } \\
\text { (BAF170) (SWI/SNF complex } 170 \mathrm{kDa} \text { subunit) (SWI/SNF-related matrix- } \\
\text { associated actin-dependent regulator of chromatin subfamily C member 2) }\end{array}$ & SMARCC2, BAF170 \\
\hline SMYD2 & $\begin{array}{l}\text { N-lysine methyltransferase SMYD2 (EC 2.1.1.-) (HSKM-B) (Histone } \\
\text { methyltransferase SMYD2) (EC 2.1.1.354) (Lysine N-methyltransferase 3C) } \\
\text { (SET and MYND domain-containing protein 2) }\end{array}$ & SMYD2, КMT3C \\
\hline HILS1 & $\begin{array}{l}\text { Putative spermatid-specific linker histone } \mathrm{H} 1 \text {-like protein ( } \mathrm{H} 1.9 \text { linker histone } \\
\text { pseudogene) }\end{array}$ & H1-9P, H1-9, HILS1 \\
\hline MRGBP & $\begin{array}{l}\text { MRG/MORF4L-binding protein (MRG-binding protein) (Up-regulated in colon } \\
\text { cancer 4) (Urcc4) }\end{array}$ & MRGBP, C20orf20 \\
\hline KAT6B & $\begin{array}{l}\text { Histone acetyltransferase KAT6B (EC 2.3.1.48) (Histone acetyltransferase } \\
\text { MOZ2) (MOZ, YBF2/SAS3, SAS2 and TIP60 protein 4) (MYST-4) (Monocytic } \\
\text { leukemia zinc finger protein-related factor) }\end{array}$ & KAT6B, KIAA0383, MORF, MOZ2, MYST4 \\
\hline
\end{tabular}

the effect of different histological types. The significant prognostic and negatively correlated gene, EYA4, has been reported to play an important role in tumorigenesis and the progression of various cancers $(29,30)$. In pancreatic ductal adenocarcinoma and hepatocellular carcinoma, EYA4 has been shown to work as a tumor suppressor gene, with its overexpression inhibiting tumor proliferation and invasion $(29,30)$. However, in this study, elevated EYA4 was found to be associated with a shortened OS in astrocytoma. A recently published study supported our result, indicating a reverse predictive role of EYA4, which promoted tumor progression as a result of the downregulation of $p 27$ Kip 1 in glioma (31). These results indicate that the expression changes of the specific genes involved in chromatin modification were notable in the development of astrocytoma.

In conclusion, this study described the systemic expression pattern of chromatin regulation genes in lowgrade astrocytoma and identified a cohort with poor prognosis. Chromatin regulation genes are significantly associated with prognosis and correlated with age, grade, and $I D H$ subtype in astrocytoma. This study has highlighted the prognostic role of chromatin regulation genes and the relevance of gene expression and biological characteristics in astrocytoma. However, further research is necessary to validate the current findings. Our results suggest that 
A

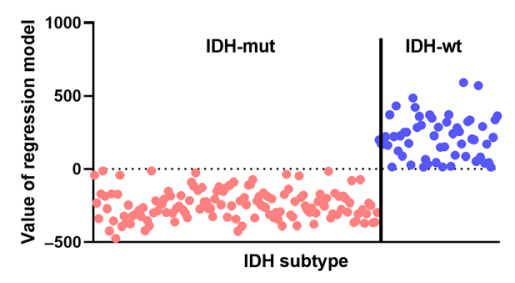

C

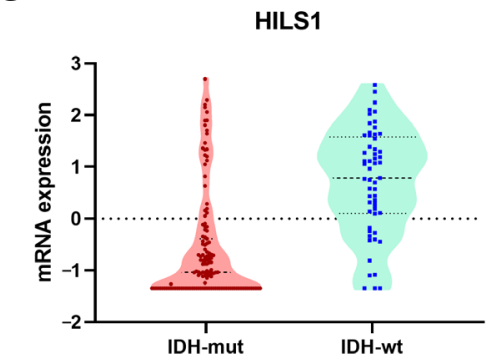

$\mathrm{E}$

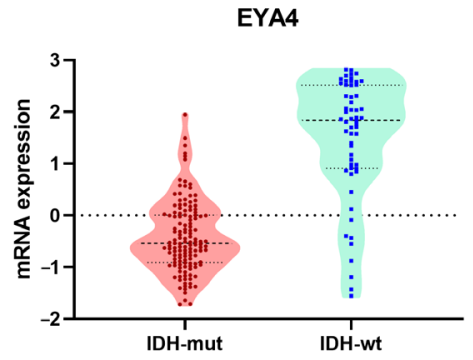

B

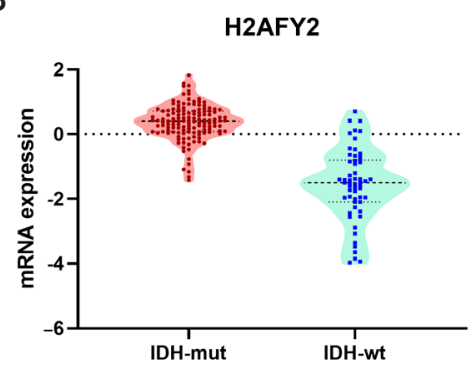

$\mathrm{D}$

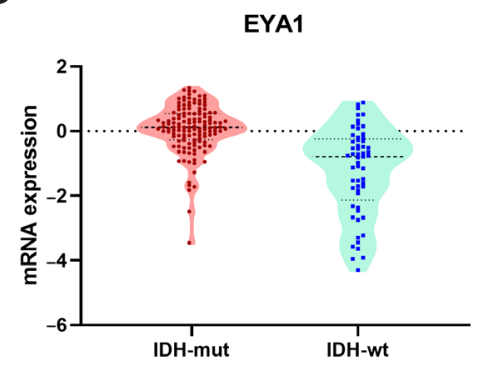

$\mathrm{F}$

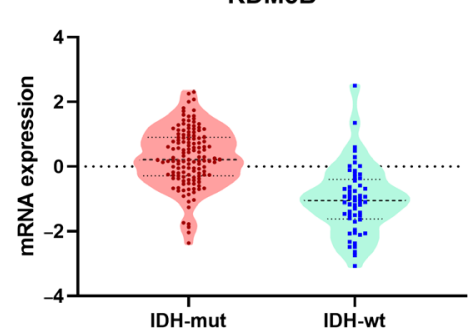

Figure 6 The chromatin regulation genes independently implicated in $I D H$-mut. (A) The regression model distinguishing the $I D H$-mut and $I D H$-wt types; (B,C,D,E,F) H2AFY2, EYA1, KDM5B, HILS1, and EYA4 exhibited different expression levels in the IDH-mut and IDH-wt types in astrocytoma. IDH, isocitrate dehydrogenase.

chromatin regulation genes have a promising role to play in the prediction of postoperative survival, and that this association with prognosis could make them important therapeutic targets in astrocytoma.

\section{Acknowledgments}

Funding: None.

\section{Footnote}

Reporting Checklist: The authors have completed the REMARK reporting checklist. Available at http://dx.doi. org/10.21037/atm-20-7229

Conflicts of Interest: All authors have completed the ICMJE uniform disclosure form (available at http://dx.doi. org/10.21037/atm-20-7229). The authors have no conflicts of interest to declare.

Ethical Statement: The authors are accountable for all aspects of the work in ensuring that questions related to the accuracy or integrity of any part of the work are appropriately investigated and resolved. All procedures performed in this study involving human participants were in accordance with the Declaration of Helsinki (as revised in 2013). All utilized public omics datasets had been generated in previous studies and obtained with prior ethical approval.

Open Access Statement: This is an Open Access article distributed in accordance with the Creative Commons Attribution-NonCommercial-NoDerivs 4.0 International 
License (CC BY-NC-ND 4.0), which permits the noncommercial replication and distribution of the article with the strict proviso that no changes or edits are made and the original work is properly cited (including links to both the formal publication through the relevant DOI and the license). See: https://creativecommons.org/licenses/by-nc-nd/4.0/.

\section{References}

1. Tan AC, Ashley DM, López GY, et al. Management of glioblastoma: State of the art and future directions. CA Cancer J Clin 2020;70:299-312.

2. Reardon DA, Rich JN, Friedman HS, et al. Recent advances in the treatment of malignant astrocytoma. J Clin Oncol 2006;24:1253-65.

3. Reed LK, Huang JH. Variability of relative cerebral blood volume measurements of recurrent glioma. Ann Transl Med 2019;7:S260.

4. Yahanda AT, Patel B, Shah AS, et al. Impact of Intraoperative Magnetic Resonance Imaging and Other Factors on Surgical Outcomes for Newly Diagnosed Grade II Astrocytomas and Oligodendrogliomas: A Multicenter Study. Neurosurgery 2020. [Epub ahead of print].

5. Franceschi E, Tosoni A, Bartolini S, et al.

Histopathological grading affects survival in patients with IDH-mutant grade II and grade III diffuse gliomas. Eur J Cancer 2020;137:10-7.

6. Richardson TE, Snuderl M, Serrano J, et al. Rapid progression to glioblastoma in a subset of IDH-mutated astrocytomas: a genome-wide analysis. J Neurooncol 2017;133:183-92.

7. Choi C, Raisanen JM, Ganji SK, et al. Prospective Longitudinal Analysis of 2-Hydroxyglutarate Magnetic Resonance Spectroscopy Identifies Broad Clinical Utility for the Management of Patients With IDH-Mutant Glioma 2016;34:4030-9.

8. Kondo Y, Katsushima K, Ohka F, et al. Epigenetic dysregulation in glioma. Cancer Sci 2014;105:363-9.

9. Zang L, Kondengaden SM, Che F, et al. Potential Epigenetic-Based Therapeutic Targets for Glioma. Front Mol Neurosci 2018;11:408.

10. Rodriguez FJ, Brosnan-Cashman JA, Allen SJ, et al. Alternative lengthening of telomeres, ATRX loss and H3-K27M mutations in histologically defined pilocytic astrocytoma with anaplasia. Brain Pathol 2019;29:126-40.

11. Bönisch C, Nieratschker SM, Orfanos NK, et al. Chromatin proteomics and epigenetic regulatory circuits. Expert Rev Proteomics 2008;5:105-19.
12. Spyropoulou A, Piperi C, Adamopoulos C, et al. Deregulated chromatin remodeling in the pathobiology of brain tumors. Neuromolecular Med 2013;15:1-24.

13. Martinez R, Esteller M. The DNA methylome of glioblastoma multiforme. Neurobiol Dis 2010;39:40-6.

14. Xie Y, Tan Y, Yang C, et al. Omics-based integrated analysis identified ATRX as a biomarker associated with glioma diagnosis and prognosis. Cancer Biol Med 2019;16:784-96.

15. Gao J, Aksoy BA, Dogrusoz U, et al. Integrative analysis of complex cancer genomics and clinical profiles using the cBioPortal. Sci Signal 2013;6:pl1.

16. Ata SK, Fang Y, Wu M, et al. Disease Gene Classification with Metagraph Representations. Methods Mol Biol 2018;1807:211-24.

17. de Hoon MJ, Imoto S, Nolan J, et al. Open source clustering software. Bioinformatics 2004;20:1453-4.

18. Saldanha AJ. Java Treeview--extensible visualization of microarray data. Bioinformatics 2004;20:3246-8.

19. Chien LN, Gittleman H, Ostrom QT, et al. Comparative Brain and Central Nervous System Tumor Incidence and Survival between the United States and Taiwan Based on Population-Based Registry. Front Public Health 2016;4:151.

20. Castro-Gamero AM, Pezuk JA, Brassesco MS, et al. G2/ $\mathrm{M}$ inhibitors as pharmacotherapeutic opportunities for glioblastoma: the old, the new, and the future. Cancer Biol Med 2018;15:354-74.

21. Shirahata M, Ono T, Stichel D, et al. Novel, improved grading system(s) for IDH-mutant astrocytic gliomas. Acta Neuropathol 2018;136:153-66.

22. Endo A, Ly T, Pippa R, et al. The Chromatin Assembly Factor Complex 1 (CAF1) and 5-Azacytidine (5-AzaC) Affect Cell Motility in Src-transformed Human Epithelial Cells. J Biol Chem 2017;292:172-84.

23. Flavahan WA, Drier Y, Liau BB, et al. Insulator dysfunction and oncogene activation in IDH mutant gliomas. Nature 2016;529:110-4.

24. Farshidfar F, Zheng S, Gingras MC, et al. Integrative Genomic Analysis of Cholangiocarcinoma Identifies Distinct IDH-Mutant Molecular Profiles. Cell Rep 2017;18:2780-94.

25. Dong Y, Zhang T, Li X, et al. Comprehensive analysis of coexpressed long noncoding RNAs and genes in breast cancer. J Obstet Gynaecol Res 2019;45:428-37.

26. Soragni E, Chou CJ, Rusche JR, et al. Mechanism of Action of 2-Aminobenzamide HDAC Inhibitors in Reversing Gene Silencing in Friedreich's Ataxia. Front 
Neurol 2015;6:44.

27. Dali-Youcef N, Froelich S, Moussallieh FM, et al. Gene expression mapping of histone deacetylases and co-factors, and correlation with survival time and 1H-HRMAS metabolomic profile in human gliomas. Sci Rep 2015;5:9087.

28. Milde T, Oehme I, Korshunov A, et al. HDAC5 and HDAC9 in medulloblastoma: novel markers for risk stratification and role in tumor cell growth. Clin Cancer Res 2010;16:3240-52.

29. Zhu XX, Li JH, Cai JP, et al. EYA4 inhibits hepatocellular

Cite this article as: Zhang $\mathrm{K}$, Zhao $\mathrm{H}$, Zhang $\mathrm{K}$, Hua C, Qin X, Xu S. Chromatin-regulating genes are associated with postoperative prognosis and isocitrate dehydrogenase mutation in astrocytoma. Ann Transl Med 2020;8(23):1594. doi: 10.21037/atm-20-7229 carcinoma by repressing MYCBP by dephosphorylating $\beta$-catenin at Ser552. Cancer Sci 2019;110:3110-21.

30. Mo SJ, Liu X, Hao XY, et al. EYA4 functions as tumor suppressor gene and prognostic marker in pancreatic ductal adenocarcinoma through $\beta$-catenin/ID2 pathway. Cancer Lett 2016;380:403-12.

31. Li Z, Qiu R, Qiu X, et al. EYA4 Promotes Cell

Proliferation Through Downregulation of p27Kip1 in Glioma. Cell Physiol Biochem 2018;49:1856-69.

(English Language Editors: D. Fitzgerald and J. Reynolds) 
Supplementary

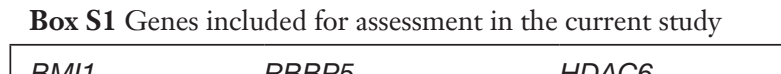

Table S1 Gene expressions correlated with subcluster order according BMI1 $\quad$ RBBP5 $\quad$ HDACE

BABAMT NSD1 KATS

CHD8 SMARCAD1 EYA3

$\begin{array}{lll}\text { BRD1 } & \text { SUV39H2 } & \text { KDM2E } \\ \text { ATRX } & \text { SMARCB1 } & \text { PRMTY }\end{array}$

BPTF NAAGO EZH

BCORL1 SATB2 DOT1L

CBX4 SMARCA1 INGA

CHD4 SMARCA4 RNF4O

PRKAA1 SATB1 BCOR

$\begin{array}{lll}\text { BRD2 } & \text { TBLIXR1 } \\ \text { BRPF3 } & \end{array}$

$\begin{array}{lll}\text { CBX2 } & \text { PRDM5 } & \text { EHMT1 } \\ \text { ABRAXAS1 } & \text { SUV39H1 } & \text { HNRNPU }\end{array}$

$\begin{array}{lll}\text { BAP1 } & \text { PRDM9 } & \text { SS18L1 }\end{array}$

BRD3 HDAC9 DMAP1

ACTLEA KMT2A FOXA3

CABIN1 KANSL1 GFIIB

$\begin{array}{lll}\text { CECR2 } & \text { KMT5B } & \text { HDAC3 } \\ \text { BRD9 } & \text { KDM6B } & \text { HDAC11 }\end{array}$

$\begin{array}{lll}\text { BRD9 } & \text { KDMGB } \\ \text { BRPF1 } & \text { KDMAE } & \text { HDAC4 }\end{array}$

BRD8 $\quad$ KDM2A HDAC5

$\begin{array}{lll}\text { CHD2 } & \text { LOXL2 } & \text { CBXZ }\end{array}$

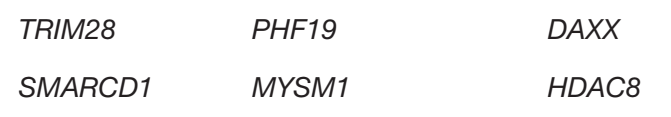

SMARCC1 PHF1 BUD23

$\begin{array}{lll}\text { SETD7 } & \text { OGT } & \text { EP400 }\end{array}$

$\begin{array}{lll}\text { SMARCA5 } & \text { KDMTB } & \text { ASH } \\ \text { TET1 } & \text { NSD3 } & \text { DPF3 }\end{array}$

TET2 PHF8

$\begin{array}{lll}\text { TLK1 } & \text { HDAC7 } & \text { FOXA1 } \\ \text { TRRAP } & \text { MSL3P1 } & \text { BANP }\end{array}$

$\begin{array}{ll}\text { HDAC2 } & \text { NPM2 } \\ \text { BEND3 }\end{array}$

HMGN5 ARID4A BRDT

RUVBL2 KMT2E UBN

$\begin{array}{lll}\text { PRDM6 } & \text { NSD2 } & \text { USP2 } \\ \text { RIOX1 } & \text { PKN1 } & \text { VPS } 2\end{array}$

$\begin{array}{lll}\text { RSBN1 JMJD6 } & \text { ZMYND11 }\end{array}$

RBBP4 PBRM1 CTCF

RING1 EYA2 $\quad$ AEBP2

PHF20 KANSL3 $\quad$ ENY2

RAG1 KAT7 EYA4

SETDB2 PRMT6 EED

RCOR1 PRKCB CARM1

RBL2 KDMAB

RCCD1 KDM5B DNMT1

MTF2 KAT6B $\quad$ ATXN7L3

L3MBTL1 MEN1 $\quad$ EHMT2

$\begin{array}{lll}\text { RBBPT } & \text { ARID4B } & \text { EYA } 1 \\ \text { KDM4C } & K D M 5 D & E Z H 1\end{array}$

LЗMBTL3 KDMAA DNA

METTL4 MORFAL1 DEK

JMJD1C ALKBH4 DPPA3

KMT5C MSL3

$\begin{array}{lll}\text { EPC2 } & \text { CHD9 }\end{array}$

NCOR1 KAT6A ANP32E

$\begin{array}{ll}\text { KMT2B } & \text { ACTL6B } \\ \text { KMT2D } & \text { KDMGA }\end{array}$

KMT2C KDM7A CHD3

$\begin{array}{lll}\text { PHF21A } & \text { MBTD1 } & \text { CHD1 } \\ \text { RB1 } & \text { MCRS1 } & \text { ASF1B }\end{array}$

$\begin{array}{lll}\text { RCBTB1 } & \text { APBB1 } \\ \text { SAAG }\end{array}$

JAK2 $\quad$ ASXL1 BABAM2

MSL1 ASH2L
CBX6

PHF2 ASF1A CBX

MORF4L2 MACROH2A1 CHDT

$\begin{array}{lll}\text { HMG20B } & \text { HIRA } & \text { BAP18 } \\ \text { CTCFL } & \text { KDM8 } & \text { COPRS }\end{array}$

H1-9P MEAFG

ING5 HCFC1 SETMAR

ARID2 MACROHZA2 UTY

КDMЗB HLTF SMARCD2

$\begin{array}{lll}\text { KDM5C } & \text { LRWD1 } & \text { RRP8 } \\ \text { PHF13 } & \text { IKZF1 } & \text { RNF8 }\end{array}$

UBE2A PRMT5 UTP3

SETDB1 KMTSA SFMBT1

SUDS3 KDM5A SMARCC2

RNF168 KDM3A ZNF304

$\begin{array}{lll}\text { SETD2 } & \text { KDM1A } & \text { SMARCE } \\ \text { WDR5 } & \text { EPC1 } & \text { TDG }\end{array}$

WAC HMG2OA DPF2

RAG2 L3MBTL2 TOX

\begin{tabular}{ll} 
TLK2 & PRKAA2 \\
\hline
\end{tabular}

RBL1 KDMAD SMYDS

TSPYL2 HASPIN TET3

RSF1 LBMBTL4

SETD5 ARID1A

SMARCD3 BAZ2A SRCAP

$\begin{array}{lll}\text { TDRDO } & \text { BAHD1 } \\ \text { USPY } & \text { SMYD2 }\end{array}$

USP22 DTX3L SMCHD1

SIRT7 KANSL2 UIMC1

SETD1B DPY3O

ARID1B
FOXA2
RHRF1

RNF2O HMGN3

BRCC3 ING3

$\begin{array}{lll}\text { SGF } 29 & \text { NR3C1 } \\ \text { PADI4 } & \text { JARID2 }\end{array}$

PRDM7 $\quad$ HDAC

\begin{tabular}{|c|c|c|}
\hline Genes & Pearson correlation & P value \\
\hline \multicolumn{3}{|c|}{ Positively correlated genes } \\
\hline HDAC5 & 0.61 & $1.80 \mathrm{E}-21$ \\
\hline PHF1 & 0.57 & $4.18 \mathrm{E}-18$ \\
\hline CCDC101 & 0.56 & $1.70 \mathrm{E}-17$ \\
\hline SMARCD3 & 0.55 & $4.38 \mathrm{E}-17$ \\
\hline EHMT2 & 0.55 & $8.14 \mathrm{E}-17$ \\
\hline ACTLGB & 0.54 & $1.83 \mathrm{E}-16$ \\
\hline H2AFY2 & 0.54 & $4.35 E-16$ \\
\hline DMAP1 & 0.52 & $2.49 E-15$ \\
\hline SMARCB1 & 0.52 & $3.36 \mathrm{E}-15$ \\
\hline TSPYL2 & 0.52 & $4.64 \mathrm{E}-15$ \\
\hline VPS72 & 0.50 & $3.91 \mathrm{E}-14$ \\
\hline CBX7 & 0.47 & $3.06 E-12$ \\
\hline NPM2 & 0.47 & $3.43 E-12$ \\
\hline MYST1 & 0.47 & $4.05 E-12$ \\
\hline HIRA & 0.46 & $5.13 \mathrm{E}-12$ \\
\hline KAT5 & 0.46 & $5.63 E-12$ \\
\hline PKN1 & 0.46 & $7.90 \mathrm{E}-12$ \\
\hline HMGN5 & 0.45 & $1.88 \mathrm{E}-11$ \\
\hline BRDQ & 0.44 & $5.97 E-11$ \\
\hline ZMYND11 & 0.44 & $7.08 \mathrm{E}-11$ \\
\hline APBB1 & 0.43 & $1.27 \mathrm{E}-10$ \\
\hline WAC & 0.41 & $1.22 \mathrm{E}-09$ \\
\hline$R C C D 1$ & 0.41 & $1.67 \mathrm{E}-09$ \\
\hline SMARCC2 & 0.41 & $1.72151 E-09$ \\
\hline \multicolumn{3}{|c|}{ Negatively correlated genes } \\
\hline PRKAA1 & -0.61 & $1.11 \mathrm{E}-21$ \\
\hline RBL1 & -0.60 & $5.86 \mathrm{E}-21$ \\
\hline RAG1 & -0.57 & $3.68 E-18$ \\
\hline CHD1 & -0.55 & $7.82 \mathrm{E}-17$ \\
\hline EYA4 & -0.54 & $1.27 \mathrm{E}-16$ \\
\hline DTX3L & -0.53 & $5.41 E-16$ \\
\hline$R B 1$ & -0.52 & $2.86 E-15$ \\
\hline DNMTЗА & -0.51 & $1.61 \mathrm{E}-14$ \\
\hline ATRX & -0.48 & $7.67 E-13$ \\
\hline USP16 & -0.47 & $2.14 \mathrm{E}-12$ \\
\hline PRMT6 & -0.47 & $2.32 E-12$ \\
\hline SFMBT1 & -0.47 & $2.78 E-12$ \\
\hline MYSM1 & -0.47 & $2.93 E-12$ \\
\hline EYA3 & -0.46 & $6.93 E-12$ \\
\hline TLK1 & -0.45 & $1.88 \mathrm{E}-11$ \\
\hline NSD1 & -0.45 & $1.88 E-11$ \\
\hline ACTLGA & -0.44 & $4.84 E-11$ \\
\hline SMARCA5 & -0.44 & $6.93 \mathrm{E}-11$ \\
\hline suz12 & -0.44 & $8.69 E-11$ \\
\hline HDACS & -0.42 & $6.83 E-10$ \\
\hline SMARCE 1 & -0.42 & $7.47 E-10$ \\
\hline$B R C C 3$ & -0.41 & $1.12 \mathrm{E}-09$ \\
\hline JAK2 & -0.41 & $1.3 \mathrm{E}-09$ \\
\hline TRRAP & -0.41 & $1.86 \mathrm{E}-09$ \\
\hline NCOR1 & -0.40 & $2.5 \mathrm{E}-09$ \\
\hline KDM5A & -0.40 & $3.24 E-09$ \\
\hline
\end{tabular}

